\title{
Signal Transduction Pathways in use of Dexamethasone Implant in the Eye
}

\author{
Yakup Cevik ${ }^{1}$, Bekir Kucuk ${ }^{2}$, Ugur Acar ${ }^{1}$, and Gungor Sobaci ${ }^{2 *}$ \\ ${ }^{1}$ Department of Ophthalmology, Ardahan State Hospital, Ardahan, Turkey \\ ${ }^{2}$ Department of Ophthalmology, Hacettepe University, Faculty of Medicine, Ankara, Turkey
}

Received: April 03, 2015; Accepted: May 11, 2015; Published: June 01, 2015

*Corresponding author: Gungor Sobaci, Department of Ophthalmology, Hacettepe University, Faculty of Medicine, Ankara, Turkey, E-Mail: gsobaci@gmail.com

\section{Summary}

Dexamethasone implant, with its durable, potent antiinflammatory, antiangiogenic, and neuroprotective properties, has gained a wide variety of therapeutic applications in ocular diseases otherwise destined for blindness; however, its mechanisms of action, including side effects, in clinical use are still under investigation. This article constitutes an up-to-date summary of knowledge on signal transduction pathways in the therapeutic use of dexamethasone implants in the eye.

\section{Introduction}

Intraocular inflammation and related complications are important causes of vision loss in posterior segment disease. Inflammatory processes cause the breakdown of the bloodretinal barrier in the case of retinal vein occlusion, uveitis, diabetic retinopathy, Irvine-Gass Syndrome, vascular leakage, and macular edema resulting in vision loss [1]. Inflammation plays a key role for neovascularization that threatens vision in posterior segment disease [2].

Glucocorticoids (glucocorticoid or corticosteroids) are used in the treatment of various inflammatory and immune diseases. Glucocorticoids have an important role in the treatment of intraocular diseases with an inflammatory origin. Thanks to their potent anti-inflammatory effects, their ability to decrease vascular permeability, inhibiting fibrin deposits and leukocyte motility, suppressing the migration of inflammatory cells, stabilizing endothelial tight junctions, inhibiting the synthesis of Vascular Endothelial Growth Factor (VEGF), Prostaglandins (PGs) and other cytokines and steroid-responsive gene transcription [3]. Intravitreal usage of a $0.7 \mathrm{mg}$ dexamethasone implant (Ozurdex ${ }^{\circledR}$ Allergan, Ireland), which is a corticosteroid with proven efficacy, obtained FDA approval in 2009 for the treatment of retinal vein occlusion, diabetic macular edema and non-infectious uveitis [4]. In this article, we aimed to explain the mechanisms of the signal transduction pathways related to the efficacy of dexamethasone implants.

\section{Glucocorticoid Receptor (Gr)}

Glucocorticoids are secreted from the adrenal gland and enter the cytoplasm directly to bind to the Glucocorticoid Receptor (GR). The GR was cloned in 1985, and is a member of the nuclear super family [5]. The nuclear receptor family which is responsible for sensing the presence of hormones, then mediating physiological and pathological processes [6]. Normally, the GR is maintained in the cytoplasm in an inactive state by heat shock proteins (hsp). When a hormone is bound, the GR dissociates from hsp90 and the receptor undergoes a conformational change and becomes active. After this, receptor is trans-located to the nucleus and the central DNA-binding domain binds to of the DNA. GR is composed of three major parts, one of them consists of the central DNA-binding domain is composed of two highly conserved zinc finger regions critical for dimerization, target site binding, transcriptional activation, and repression [7,8]. New data indicate that translocation of the GR from the cytoplasm to the nucleus occurs without hormone binding [9]. This can result in one of two basic changes on the gene expression in the nucleus. The Glucocorticoid Response Elements (GRE) in the promoter domain of the GR target gene can bind to the dimer such that gene transcription is called trans-activation. These sequences are located in the 5' promoter domain in the target gene. Interaction of the GRE domains and certain co-activators with the DNA double helix and GR-glucocorticoid dimers result in gene transcription (trans-activation) induction [10]. Alternatively, the receptor can also suppress the gene, which is called transrepression. It has been shown that interaction between other activation factors, including activator protein-1 (AP-1) and the GR, blocks the activities of the GR independently of the binding points on DNA. Binding to ligand activating receptors for a GRE can prevent binding of other activation factors to their promoter elements, or the GRE can directly bind to activated GR, AP-1 or other transcription factors including the nuclear factor (NF$\mathrm{KB})$ to protect them from active gene expression. As a matter of fact, since most of the cytokine gene promoters are not GRE, this second mechanism plays a role in the regulation of cytokine expression. Although many details have not been fully elucidated, more specific drugs for targeting inflammation are being developed based on these new advancements [11]. Interaction of the GR homodimer and GRE can increase transcription. However, it is not clearly known how this process is affected by the 
glucocorticoid dosage or cell type. The mechanism of the adverse effects of glucocorticoid has not been identified yet [12].

Coding of the GR is located on the long arm of the $5^{\text {th }}$ chromosome (domain 5q31-32). The genomic structure includes 9 exons with 3 separate gene promoters [13]. Although it cannot be explained why different cell types use different promoters, the reason may be attributed to GR regulation specific to the cell type.

The GR is a member of the super family included in mineralocorticoid, thyroid hormone, sex hormone, retinoic acid, and vitamin D receptors. GR is built as a modular protein, uniting the following functional building blocks: a N-terminal transactivation domain (NTD), a hinge region, a pair of zincfinger motifs in the conserved DNA-binding domain (DBD) and a C-terminal ligand-binding domain (LBD) [14]. The N-terminal contains a domain with independent Activation Function (AF) 1. This AF domain accompanies the transcriptional activity, and binds transcriptional factors and co-activator proteins. The C-terminal contains the AF-2 domain, which is capable of interacting with other co-activators related to hormone binding and gene transcription $[10,13]$.

GRs have two different isoforms; of these, the GR $\alpha$ consists of 777 amino acids and the GR $\beta$ consists of 742 amino acids [15]. Both forms are found together in almost all human tissues. GR $\alpha$ is the predominant isoform and can bind to only one hormone, and is capable of inducing or inhibiting only one gene. GR $\beta$ allows for the formation of alternative GRs in pre-RNA transcripts and differs from the GR $\alpha$ isoform with only one amino acid in the C-terminal. This difference in GR $\beta$ probably does not ensure protection from hormone binding. This function is the subject matter of scientific debate about the actual importance of the $\beta$ isoform in the clinical response to glucocorticoids, since the up-regulation of the $\beta$ isoform results in a strong inhibition of the active isoform through a competitive mechanism, therefore reducing the glucocorticoid effectiveness. However, there are inconsistent data on this matter [16].

Oligomeric complex proteins of inactive GR in the cytoplasm include hsp90 (approximately 90kDa) including two subunits bound to the C-terminal of GRs, immunophilin p59, and the small p23 phosphoprotein. Interaction between GRs and hsp90 is required for the duties related to nuclear translocation to ensure migration of the activated GR to the nucleus, and for maintaining the configuration of the C-terminal hormone binding domain [17].

The anti-inflammatory activity of glucocorticoids causes, mainly, the repression of pro-inflammatory genes, i.e., those genes that strengthen the inflammatory response, including apoptosis induced by cytokines and leukocytes. Furthermore, glucocorticoids induce the expression of tight junction genes. Three families of transmembrane proteins, the claudin family, the JAM family and the MARVEL domain containing proteins tricellulin and occludin are responsible for cell-to-cell attachment in the establishment of the TJ barrier [18-20]. One of the results of this experimental study that is the increased expression of the TJ genes occludin and claudin- 5 is the result of the transactivation by the GR, the physical outcome could be considered antiinflammatory, through a decrease in solute flux and edema in the tissues surrounding the vasculature [21].

The edema-reducing effects of glucocorticoids were investigated on epithelial cells. It was found that dexamethasone increased Trans-Endothelial Electrical Resistance (TEER) in breast epithelial cells, and decreased the passage of mannitol through epithelial cells. Dexamethasone also reduces edema in pulmonary epithelial cells directly through cellular permeability. Based on these data, it was suggested that dexamethasone could be effective for treating retinal edema in the eye.

There are 10 to 100 genes for which glucocorticoids are thought to influence the genetic regulation. There are data indicating that the glucocorticoid-GR complex is effective on gene regulation through the induction of anti-inflammatory protein synthesis and, more importantly, through the mediation of a trans-repression mechanism. These mechanisms include pro-inflammatory transcriptional factors such as NF-Kb or AP-1, and direct inhibition of destabilization enzymes such as MitogenActivated Protein Kinases (MAPKs), gene expression, and the cellular proliferation throughout the inflammatory process. In mammalian cells, there are three well-characterised MAPK families: the Extracellular Signal-Regulated Kinases (ERKs), c Jun N-terminal Kinases (JNKs) and p38s [22]. MAPK pathways are organized as parallel kinase cascades, in which activation is mediated by sequential phosphorylation events. The JNK and p38 pathways are strongly activated by pro-inflammatory stimuli and regulate many aspects of inflammation and immunity, including the expression of pro-inflammatory genes and the activation or differentiation of T cells [23-25]. In addition, activation of histone acetyl transferase and histone deactylase enzymes responsible for chromatin configuration can also contribute $[13,26]$. In this experimental study that is activated GR may directly bind to CBP or other coactivators to inhibit their histone acetyltransferase activity thus preventing the subsequent histone acetylation and chromatin remodelling. More importantly, particularly at low concentrations that are likely to be relevant therapeutically in asthma treatment, activated GR recruits corepressor proteins, such as histone deacetylase 2 , to the activated inflammatory gene transcriptional complex, resulting in deacetylation of histones and, thus, a decrease in inflammatory gene transcription [27].

Regulating effects of some glucocorticoids occur within minutes, for which genomic effect is insufficient to explain and requires the contribution of nongenomic effect. Three nongenomic mechanisms with different speeds have been defined for glucocorticoids [28-30]. Non-genomic effects may prepare the cell for subsequent glucocorticoid-induced genomic changes, bridge the gap between the early need of change and the delay in the expression of genomic effects and may induce specific changes that in some instances are opposite to those induced by genomic mechanisms.

\section{Non-genomic effects mediated by cytosolic GR}

In the experimental study investigating this matter, it was observed that epidermal growth factor stimulating cytosolic 
phospholipase- 2 enzyme was rapidly inhibited by dexamethasone [31]. It is thought that this effect resulted from the occupied/ bound cytosolic GR; however, the observed effect is sensitive to RU486 (glucocorticoid receptor antagonist [17 $\beta 3$-hydroxy-ll $\beta$ (4-dimethylamino phenyl) $17 \alpha$-(l-propynyl) estra-4,9-dien-3one]) [32] even without any change on gene transcription, but insensitive to actinomycin (transcription-independent). It can be said that chaperon or co-chaperone multiprotein complexes mediate this effect. In addition, this can result in the nontranscriptional activation of cytosolic GRs that glucocorticoids bind to by phosphatidylinositol 3-kinase, protein kinase, and endothelial nitric oxide synthase.

\section{Non-specific nongenomic effects}

Physicochemical changes cause interactions between biologic membranes, and this possibly contributes to the therapeutic effect [28]. Glucocorticoids can change the physicochemical properties of biological membranes, especially plasma and mitochondrial membranes. Glucocorticoids are thought to intercalate into these membranes and change the function of membraneassociated proteins, thereby affecting lipid peroxidation and membrane permeability [28,29]. In immune cells, the interaction of glucocorticoids with plasma membranes results in rapidly reduced calcium and sodium cycling across the membranes, which, in turn, is thought to contribute to immunosuppression and the reduction of inflammation. Glucocorticoids also diminish ATP production by inhibiting oxidative phosphorylation and by increasing mitochondrial proton leak. ATP is essential to immune cells for cytokine synthesis, migration, phagocytosis, and antigen processing and presentation [33]. Impairment of ATP production might, therefore, also contribute to the pronounced antiinflammatory and immunosuppressive effects produced by high glucocorticoid dosages.

\section{Specific non-genomic effect}

Glucocorticoids cause specific nongenomic effects that are mediated by Membrane-Bound Glucocorticoid Receptors (mGCR). Binding sites in membranes have been characterized that displaying binding features compatible with an involvement in rapid steroid signaling. Evidence of nongenomic steroid effects and distinct receptors involved is available for glucocorticoids, mineralocorticoids, gonadal hormones, vitamin $\mathrm{D}$, and thyroid hormones [28,29,34]. For glucocorticoids, however, mGCR have so far been detected only in amphibian brain [35], and on leukemic/ lymphoma cells [36-38], human peripheral blood mononuclear cells [34]. Transport and up-regulation of the membrane GR are activated after immunostimulation. It was seen that it showed positive correlation with the disease activity in rheumatoid arthritis [34]. Recent studies have revealed the existence of mGCRs in human T cells, and provided insight into the functional role of these receptors.Dexamethasone was found to inhibit T-cell receptor signaling through its effects on the mGCRmultiprotein complex. Dexamethasone targeting of mGCRs results in inhibition of the enzymatic activities of lymphocytespecific protein tyrosine kinase and Fyn, components of the mGCR-multiprotein complex that have key roles in initiating T-cell receptor signaling and, therefore, subsequent cytokine synthesis, cellular migration or proliferation $[39,40]$. Function(s) of membrane associated GRs are not clear; observations indicate that their role in the pathogenesis of the disease can be, in fact, negative.

\section{Anti-Inflammatory Effects of Dexamethasone}

Ophthalmic tissues have membrane phospholipids are widely recognized that phospholipids play multiple roles in cell processes. Their primary function is to define the permeability barrier of cells and organelles by forming a phospholipid bilayer. This bilayer serves as the matrix and support for a vast array of proteins involved in important functions of the cell such as energy transduction, signal transduction, solute transport, DNA replication, protein targeting and trafficking, cell-cell recognition, secretion, etc. Secondary messengers derived from membrane phospholipids play an important role in the regulation of normal cellular functions and in the defense/inflammation response. Secondary messages mainly regulate the cellular functions through signal transduction by a) remodeling of receptors and ion channels on the cell; b) extracellular matrix remodeling; c) via cytoplasmic signals, e.g., modulation of protein kinase cascade; and d) gene expression. PG and platelet activating factor (PAF) are effective for the initiation, maintenance and enhancement of inflammation and immune responses. In this experimental study, PGs, the products of cyclooxygenase pathway, are proangiogenic factors that are implicated in vascular permeability and angiogenesis [41].

\section{Arachidonic acid metabolism in the Eye}

Arachidonic acid (AA) precursors are the precursors of a wide group of potent bioactive lipid mediators. The free AA pool is normally found in all ophthalmic tissues in insignificant amounts and kept under strict control. Basal AA metabolism and turnover are found under physiologic conditions. Exposure to high glucose concentration induces the production of inflammatory mediators via the cyclooxygenase pathway in rat retinal endothelial cells [42], human retinal pericytes, and human retinal microvascular endothelial cells [43]. This cellular signal changes result from the catabolism of the excessive AA and other fatty acids from membrane phospholipids through the activation of phospholipases within the inflammation and immune response process. From this, PGs, prostacyclins and thromboxanes form via the cyclooxygenase pathway and leukotrienes, lipoxins and Hydroxyeicosatetraenoic acid (HETEs) form via the lipoxygenase pathway [44]. Products of arachidonic acid metabolism via cyclooxygenase (PGs, prostacyclin, and thromboxane), known to play a major role in the intraocular inflammation process [45], are capable of inducing VEGF expression. The entire studies specific to the eye have shown that the cyclooxygenase pathway is more active in the eye [46].

Two cyclooxygenase enzymes have been defined, which are encoded from two different genes: the structural enzyme, COX-1, and the inducible COX-2 enzyme. COX-2 is also called the mitogen inducible enzyme; the reason for this is that its expression stimulates the synthesis of cytokines and mitogens including bFGF [47], TNF $\alpha$ [48], IL-1B [49] and pp60 [50]. It is currently 
believed that COX-1 enzyme is structural and produces PG under physiologic conditions, and COX-2 is up-regulated under pathophysiologic conditions [51]. In retinal diseases, ischemia is a common precursor to neovascularization. It was shown that early pro-inflammatory genes are predominantly expressed in ischemic retina. One of these genes expressed at high levels during the early stages of the disease is cyclooxygenase-2, whose expression is induced by cytokines, mitogens, and endotoxins [52]. COX-2 also stimulates inflammation through initial gene production [52]. COX-2 is expressed in a developmental fashion, and an ischemic retina is the stimulator for this [53]. Roles for COX-2 have been established in tumors $[54,55]$ and in corneal neovascularization [56]. While inhibition of COX-2 decreased preretinal neovascularization significantly; inhibition of COX-1 was found to be ineffective $[57,58]$. It is known that glucocorticoids inhibit the induction of COX-2 in most systems [59].

This human study is that PGs stabilize the $\mathrm{PgE}_{2}$ hypoxia inducible factor (HIF) [60] and in the animal studies it is shown, to stimulate the secretion of basic regulators of angiogenesis including VEGF by neural cells, including ganglion, Müller, and retinal pigment epithelium cells and therefore ensure endothelial cell proliferation [61]. It was observed that inhibition of COX-2 resulted in the decrease of retinal effects of PGE3, which is a COX product [62].

The lipooxygenase pathway has a number of different functions. Lipoxins are the very potent superoxide mediators of the 15-lipoxygenase pathway that ensure neutrophil degranulation, and are synthesized via this pathway. The 5-lipoxygenase pathway turns the very potent chemotaxis factor 5-HPETE to 5-HETE. 5-HPETE also has the function of acting as a substrate for Leukotrienes (LT), and it is known that LTs increase permeability in small vessels [44].

Glucocorticoids are the most extensively studied drug groups among anti-inflammatory drugs. Glucocorticoids bind to intracellular receptors and affect inflammation by inhibiting the synthesis of immunoregulator proteins, including cytokines. Glucocorticoids play an important role in preventing inflammation by suppressing cytokines (IL-6, -8, -1ß, TNF, sIL2R, IL-12), lymphotoxins, chemokines (MCP-1, chemokine receptor-2,-5) and soluble ICAM-1. The response is generally directly connected to the bound steroid receptor number and, therefore, it is dose-dependent [63].

Glucocorticoids have been found to be related to numerous inhibitor pathways. Although a small number of genes can be regulated directly, many more genes are regulated indirectly bythe GCR via suppression of gene expression, a process known as transrepression. Glucocorticoids suppress the activity of the cytokine gene (as with IL-1, IL-2, IL-3, IL-8), reducing cytokine secretion (IL-1), destabilizing the cytokine mRNA via AU (Adenine Uracil) sequences of 3'-untranslated domains (IL-1, TNF, GMCSF) and inactivating or binding to cytokines (IL-1) through the induction of false receptors [64].

In an animal study investigating the relationship between the weakening of the blood-retinal barrier related to diabetes and leukocyte accumulation, it was found that leakage was two-fold greater in the diabetic group, as compared to the control group. In the intravitreal dexamethasone injection group, however, the leakage was reduced by $47.5 \%$, as compared to the diabetic group. The increase in the levels of cytokine receptor (IL-2R $\alpha$, IL-4R $\alpha$, IL-6R $\alpha$, IFN- $\gamma R$, GM-CSFR $\alpha$, CSF-1R, TNF-R) induced by glucocorticoids was accompanied by the increase in receptor mRNA $[65,66]$. Molecular mechanismsby which glucocorticoids inhibit cytokines are reported to be at the level of transcription, translation, mRNA stability and secretion [66].

It is believed that the inhibitor effect of glucocorticoids on NF$\mathrm{kB}$ is a key step for the anti-inflammatory and immunosuppressive actions. A few mechanisms have been suggested for inhibition. One of these, the direct protein-protein interaction between NF-kB and GRs, is important for the mutual transcriptional antagonism between NF-kB and GRs or the cross-repression of the cAMP response element binding protein (CREBP) [67] and the catalytic protein kinase A subunit [68]. Glucocorticoids inhibit transcriptional up-regulation of T cell-derived cytokines, such as IL1-2, IL-4, IL-10, and g-interferon (1-3), and proinflammatory cytokines, such as IL-1, granulocyte-macrophage colonystimulating factor, and tumor necrosis factor- $\alpha[69,70]$. Another target of glucocorticoids in T cells is Fas ligand (FasL), a membrane protein that triggers apoptosis of mature $\mathrm{T}$ cells by engaging Fas $[71,72]$. AP-1 mediates the IL-2 gene expression through the NF$\mathrm{kB}$ synergism activated by T-cells. GR suppression reduces the synergism and Glucocorticoid-Induced Leucine Zipper (GILZ) gene transcription induced by glucocorticoids can be required [73]. This experimental study, Glucocorticoids suppress the IFN-y gene through the mediation of GR together with AP-1, CREBP and activated transcription factor complexes [74].

In an animal study on diabetic retinopathy, it was seen that the proportion of leukocytes reduced by $48 \%$ within 48 hours following the dexamethasone administration [65]. It is understood from these data that glucocorticoids or dexamethasone provides the anti-inflammatory effects via several pathways.

\section{Anti-Vascular Endothelial Growth Factor (Vegf) (Anti-Angiogenesis) Effect of Dexamethasone}

Angiogenesis is a dynamic process resulting in new vessel formation by the endothelial cells $[75,76]$. Angiogenesis plays the principal role in the development of human tissues and wound healing [75,76]. Although abnormal angiogenesis results in neovascularization, it also plays an important role in many systemic diseases and tumor pathogenesis [77]. Neovascularization involves proliferative retinopathies and agerelated macular degeneration. According to recent developments, targeted therapy, vascular endothelial growth factor (VEGF) is a trademark [78]. Development of this treatment modality started in 1948 when Michelson reported that VEGF, which was named factor $\mathrm{X}$ initially and secreted from the ischemic retina, was required for the development and growth of new vessels. Judah Folkman stated that tumor angiogenesis was required for tumor growth and that inhibition of angiogenesis would be a very good treatment strategy in 1971 [79]. VEGF was defined as the main 
regulator for physiologic and pathologic processes in the eye years later [78].

Several forms of VEGF have been defined: VEGF-A, VEGF-B, VEGF-C, VEGF-D, VEGF-E and Placental Growth Factor (PIGF) derive from the same gene family [80]. VEGF-A family appears to be more relevant for vascular proliferation and, therefore, it has attracted more attention. Naming of the four main isoforms in this family (VEGF 121, 165, 189, 206) was made according to the number of amino acids following the dividing signal [81]. VEGF is also known as the vascular permeability factor and its receptor is located on the vascular endothelial cell surface. There are three types of VEGF tyrosine kinase receptors on the endothelial cell surface: VEGF receptor-1, 2, and 3. Once bound to the VEGF receptor, a series of signal changes related to permeability, endothelial cell migration and angiogenesis start. VEGF-A binds VEGFR-1 and VEGFR-2, while VEGF-B and PIGF binds only VEGFR-1. When bound to the VEGF receptor, activated VEGF receptors stimulate the mammalian target of the rapamycin (the AKT/mTOR) signal pathway via phosphatidylinositol-3-kinase (PI3K) and ensure mTOR complex formation and additional phosphorylation $[82,83]$.

VEGF is found in ganglion cells, Müller cells and pigment epithelial cells in the eye. Hypoxic conditions increase VEGF production [84]. Both VEGF receptor 1 and VEGF receptor 2 are located primarily in vascular endothelial cells [85]. VEGF 165 is the most abundant isoform among different isoforms. In animal models, VEGF 164 (equivalent to 165 in humans) selectively stimulates inflammation and cellular immunity in a pathological neovascularization process [86]. While VEGF 110 increases vascular permeability and stimulates endothelial cell growth, its effects were not found to be as potent as the effects of VEGF 165 [87].

Folkman et al. [88] reported for the first time in 1983 that formation of new blood vessels in heparinized rabbit corneas was suppressed by cortisone. Following this, heparin bound corticosteroids, glucocorticoids, cortisone metabolites, squalamine and estrogen metabolites were known as angiostatic steroids.

Evidence that endogen glucocorticoids contribute to the regulation of new vessel formation is accumulating [89]. While the glucocorticoid concentrations in the target tissues regards receptor regulation (11ß-hydroxyteroid dehydrogenase isoforms) are related to both physiologic and pathophysiologic angiogenesis [90], excess of glucocorticoids can impede wound healing [91]. Although glucocorticoids are capable of inhibiting the tube formation in endothelial cell cultures directly [92], it has not been clarified yet that glucocorticoids can inhibit remodeling, proliferation and/or migration of endothelial cells and positioned in the centre of which angiogenesis is unknown [93]. Together, effects resembling the inhibition of proliferation and migration on vascular smooth muscle cells were observed on endothelial cells. It has been suggested in previous studies that glucocorticoids inhibit angiogenesis and production of VEGF and PGs. It was observed in a study that glucocorticoids blocked the tubule-like structure of the vessel, PGF2 $\alpha$, induced VEGF, and basal VEGF. VEGF and prostanoids stimulate angiogenesis with different secondary messenger pathways (cyclic adenosine monophosphate and phospholipase Cy-Ras-Raf, respectively). It has been suggested that glucocorticoids are in effect at the end of the angiogenesis pathway. It is therefore seen that the 'downstream' effect is on cellular morphology, migration and proliferation. In this experimental study, it was also observed that dexamethasone directly inhibited the tubal-like formation formed with the mediation of the GR [90]. Dexamethasone-mediated changes on the cellular skeleton involving microfilament or microtubule structures were prevented through suppression of key angiogenic responses [94]. It has been observed that glucocorticoids exert their effects by changing cellular morphology and intercellular connections [95].

Glucocorticoids directly inhibit VEGF-A expression in vivo and in vitro. It has been found that prednisone at a $100 \mathrm{ng} / \mathrm{ml}$ concentration induces retinal pigment epithelial proliferation and inhibits VEGF-A. Furthermore, it has been observed in animal models that IVTA (intravitreal triamcinolone acetonide) significantly suppresses the choroidal neovascularization, optic disk neovascularization and pre-retinal neo-vascularization.

In another animal study, ICAM-1 and VEGF mRNA expressions were up-regulated in the diabetic group, and significantly suppressed 48 hours following the dexamethasone administration [65]. ICAM-1 and VEGF protein levels were $76.74 \mathrm{pg} / \mathrm{mg}$ in the untreated DM group, which was higher than the control group. When the ICAM-1 protein level was compared with the diabetic group, it was seen that this was significantly lowered by dexamethasone [65]. In another experimental study, dexamethasone affected the vascular permeability caused by brain tumors in relation with the GR mechanism by decreasing the response to permeability factors of tumoral origin, and by reducing the vascular permeability factor release from tumoral cells [96]. In yet another study, dexamethasone increased angiopoetin-1 and increased VEGF in human brain astrocytes and pericytes. In the same study, RU486 reduced the angiopoetin-1 and VEGF regulation induced by dexamethasone. Again in the same study, no changes were seen on angiopoetin-1 and VEGF mRNA stability, suggesting that dexamethasone regulated angiopoetin-1 and VEGF through transcription [97]. Glucocorticoids show most of their effects in the cell through activation of GRs by binding specific ligands, glucocorticoid hormones and dexamethasone [98]. In this experimental study, RU486, which are a GR antagonist, completely inhibited Ang1 and VEGF regulation induced by dexamethasone through GR [97]. What is known is that the activated GR shows its effects through gene transcription $[98,99]$. However, effects of GR appeared without transcriptional modulation [100]. In this experimental study, transcriptional regulation of Ang-1 and VEGF by dexamethasone occurred via Ang-1 up-regulation and VEGF down-regulation, because dexamethasone did not affect Ang-1 and VEGF mRNA stabilities [97]. In has been shown in several studies that glucocorticoid induced down-regulation of VEGF in many diverse cell types including keratocytes 
[101], microvascular endothelial cells in hypoxic brain [102], chondrocytes [103] and Müller cells [104]. In this study, it has been shown that dexamethasone down-regulates Ang-1, which is a potent stabilizer of the blood-brain barrier, and VEGF, which is a potent permeability increaser, down-regulates in similar ways. [97].

\section{Effects of Dexamethasone on Tight Junction Proteins}

The blood-retina barrier consists of retinal vessels and retinal pigment epithelial cells and has the function of controlling the water and solute flow, and keeping the inflammatory cells and antibodies from entering [105]. The barrier of the retinal vessels is formed by the endothelial cells and includes numerous tight junctions that form a selective barrier against water and solute flow between the vessel and adjacent cells. Interruption of this barrier directly results in macular edema and loss of vision occurs as a result.

Two types of transmembrane proteins, namely, the occludin and claudin family are directly responsible for the formation of tight junction barriers between cells [106]. Occludin is mostly expressed in epithelial and endothelial cells (not in the neural retina) and correlated with the properties of this barrier [107]. Since occludin is a membrane protein, it is equivalent to the tight junction in the intramembranous structure. Therefore, the closer it is to the cellular surface, the better correlated it is with barrier function in the tight junction [108]. At least 23 isoforms of claudins have been defined. They are responsible for the movements of small molecules and ions, which are characteristic of these tight junction complexes. Numerous claudins form tight junction complexes with different characteristics in different tissues $[109,110]$.

These are isolated from tight junction complexes and play specific roles in the architecture and arrangement of the junction. Proteins of the wide zonula occludens (ZO-1, 2 and 3) ensure communication with the junction complex within the cell and communication between the components of the cellular skeleton $[111,112]$. More tight-junction complexes are being defined in studies. In conclusion, tight junction proteins play a key role in the regulation of the blood-retina barrier.

Multiple effects of glucocorticoids on endothelial junction complexes have been observed, and most of these have been evaluated in vitro. Glucocorticoids protect the retina-blood barrier by strengthening the junction complexes, decreasing Para-cellular permeability and increasing the monolayer TEER [113]. TEER reflects the para-cellular permeability and confluence in cell layers in vivo and in vitro; therefore, it provides a measure of the integrity of the tight junction complexes [113]. Hydrocortisone decreases the transport of water and solutes in bovine retinal endothelial mono-layer cells, and increases the expression of ZO-1 and occludin tight junction proteins in the cell margins [114]. In human endothelial cells, dexamethasone suppresses the down-regulation of claudin-5 mainly induced by thapsigargin, TEER reduction, and leakage with FITC dextrane addition [115]. In another study on the effects of dexamethasone on the blood-brain barrier, it was seen that it decreased paracellular permeability. Permeability difference according to pore theory is consistent with the reduction in pore number between the endothelial cells in the brain. This effect is accompanied by the filamentous actin and cortactin concentration at the periphery of the cell. Tight junction protein Z0-1 develops simultaneously and ZO-1 and occludin expression increase to accompany this. In contrast, no changes were observed on the adherence proteins $\beta$-catenin and p100/p120 [116].

In a well-designed study, it was observed that rat monolayer retina vascular endothelial cells were positively stained with immunofluoresecens dye for vW factor. It was observed that the TEER value in the dexamethasone treatment group was higher than that of the control group. It was observed that tight junction proteins in the dexamethasone group were closer to the margins in retina vascular endothelial cells, as compared to the control group. It was also observed that claudin-1 mRNA level in the dexamethasone groups was higher than that of the control group. It is stated in the conclusion section of this study that dexamethasone strengthens the tight junctions in the vascular endothelial cells of the retina and, therefore, it is one of the treatment mechanisms for macular edema by glucocorticoids [117].

Glucocorticoids inhibit the tight junction phosphorylation proteins induced by VEGF-A. Glucocorticoids also develop the properties of the Blood-Retinal Barrier (BRB) [114]. It has been observed that occludin phosphorylation was reduced after 4 hours following the initiation of glucocorticoid treatment, and occludin expression was increased simultaneously in the bovine retinal endothelial cell layer [114]. In another study, hydrocortisone was seen to improve the barrier function significantly, together with the immune-reactive ZO-1. Occludin increases in the in vitro vascular endothelial barrier models, and it was observed that occludin mRNA increased. It was also shown that it was hydrocortisone that caused occludin dephosphorylation [114].

One of the ways that glucocorticoids protect the properties of tight junctions is through the Ras-dependent pathway. Ras family proteins consist of small GTPase proteins and these play a role in the cell-to-cell interactions [118].

\section{Neuro-Protective Effect of Dexamethasone}

Glucocorticoids are used in clinical studies, and in studies with animal models with therapeutic purposes in central nervous system injuries. Reduction in damage with pre-treatment of glucocorticoids in ischemic cerebral neural injury has been shown in clinical studies and in animal models [119]. Glucocorticoids also have protective (anti-apoptotic) effects on the neural retina. It was seen on rabbit models that IVTA injection protected the retinal photoreceptors from apoptosis after sub retinal hemorrhage [120]. A similar result was seen in the reduction by glucocorticoids of photoreceptor apoptosis induced with light in rabbits, most likely through activator protein-1 suppression with the GR activation [121].

One of the key properties of diabetic retinopathy is that there is neuronal dysfunction in the retina. It has been shown that the 
intrinsic mitochondrial caspase-bound apoptotic pathway is included in the neuronal degeneration induced by hyperglycemia [121]. In the early rat diabetic models, phosphorylated mitogenactivated protein kinase p38 (p38MAPK), the key regulator of apoptosis, CASPASE-3, releases polimerase- 1 from its substrate and neuronal apoptosis in the retina results. Glucocorticoids ensure the GR activation together with the inhibition of p38MAPK phosphorylation [122,123].

Another neuroprotective property of glucocorticoids is the increase of glutamine synthetase (GS) expression, and the important role played by this enzyme through formation of ammonia from glutamine in Müller cells of the neuronal retina, and in nitrogen metabolism through glutamate metabolism [124]. Though glutamate, which is an amino acid, is the main excitatory transmitter in retina, glutumate is neurotoxic and causes neuronal death [125] and ischemic neuronal injury in rat brain [126]. Significant cortical neuron destruction was observed with exposure to $100 \mu \mathrm{M}$ glutumate for only 5 minutes in this in vitro study [118]. It was seen that the toxic effect was on the internal retina layer [118]. Based on this, it was concluded that glutamate metabolism is important for neurons, and it was shown both in vivo and in vitro that glucocorticoids increased the GS activity [127]. Furthermore, in an in vitro study, we had shown that dexamethasone could have toxic effects, even in low dosages similar to those used in the clinical setting [128].

\section{Dexamethasone Resistance}

The reason for the lack of adequate response to dexamethasone in some clinical applications of intravitreal dexamethasone implant could be due to drug resistance, which has been investigated in other tissues. Recovery of Th17 lymphocytes and accompanying cytokines in the inflamed airways of patients with severe asthma in a study suggested that these play an important role in severe asthma pathogenesis [129]. Although not well-defined, it was seen that the role of these were important for promoting steroid resistance $[130,131]$. Steroid resistance in asthmatic patients has been explained by means of several mechanisms $[123,132]$. The first of these is that of high levels of GR- $\beta$ - the dominant negative regulator of the active GR- $\alpha$ - causing the formation of inactive heterodimers, resulting in a reduced steroid response [133-136]. The general idea is that GR- $\beta$ has a negative role in the regulation of GR- $\alpha$. The reason for this has been indicated as the much lower results obtained in studies as regards the expressions of GR- $\beta$ protein and mRNA $[130,133,137]$. However, other studies have indicated that GR- $\beta$ was in equal or higher concentrations, as compared to GR- $\alpha$ in various tissues and organs $[138,139]$. In yet another study, GR- $\beta$ protein levels increased under the stimulation of IL-17, and were found to be lower in abundance than GR- $\alpha$ protein [129]. Although there are other studies claiming that it has different effects on gene expression to those of GR- $\alpha$, it appears that further studies are needed to understand the steroid resistance of GR- $\beta[137,140]$.

The best describes the mechanism of glucocorticoid resistance, which is included in the GR failure in gene transcription regulation. GR genes include multiple variants:
GR $\alpha$ (the most abundant isoform), GR $\beta$, GR-A, GR-P and GRy. GR $\beta$ lacks a functional ligand domain [141]; however, it gains the dominant negative heterodimer form together with GR $\alpha$. This heterodimer protects the binding domains and co-activators or repressors from GR target gene repression in a competitive way [142]. In a study, the reason for high GR $\beta$ expression was stated as the genetic polymorphism of exon9 $\beta$ resulting in the stabilization of GR $\beta$ transcript $[143,144]$. Again, although this is not sufficient to explain the acquired glucocorticoid resistance, in fact, the up-regulation of GR $\beta$ caused by combined inflammatory cytokines (TNF $\alpha$ and INFy) causes the glucocorticoid resistance [145]. What is more important than the total expression of GR $\alpha$ / GR $\beta$, it was seen that up-regulation of GR $\beta$ upon decrease in the GR $\alpha$ expression had a similar effect [129].

\section{Conclusion}

In this study, we have tried to review the mechanisms of dexamethasone action through different signal pathways. The dexamethasone has evidence for efficacy in multiple clinical situations, including macular edema associated with Retinal Vein Occlusion (RVO), macular edema associated with uveitis or Irvine-Gass syndrome, diabetic macular edema in vitrectomized eyes, persistent macular edema, noninfectious vitritis, and as adjunctive therapy for age-related macular degeneration. Safety concerns include cataract formation and intraocular pressure elevation that is most often temporary and amenable to medical management. However, some of these therapeutic effects and side effects require further research.

\section{References}

1. Johnson MW. Etiology and treatment of macular edema. Am J Ophthalmol. 2009; 147: 11-21. doi: 10.1016/j.ajo.2008.07.024.

2. Lowder CY, Hollander DA. Review of the Drug-infused Eye Implantâ Ozurdex $^{\circledR}$ (Dexamethasone Intravitreal Implant). US Ophthalmic Review. 2011; 4(2): 107-112.

3. London NJ, Chiang A, Haller JA. The dexamethasone drug delivery system: indications and evidence. Adv Ther. 2011; 28: 351-366. doi: 10.1007/s12325-011-0019-z.

4. Kapoor KG, Wagner MG, Wagner AL. The Sustained-Release Dexamethasone Implant: Expanding Indications in Vitreoretinal Disease. Semin Ophthalmol. 2014 Mar 21. [Epub ahead of print].

5. Hollenberg SM, Weinberger C, Ong ES, Cerelli G, Oro A, Lebo R, et al. Primary structure and expression of a functional human glucocorticoid receptor cDNA. Nature. 1985; 318(6014): 635-641.

6. Necela BM, Cidlowski JA. Mechanisms of glucocorticoid receptor action in noninflammatory and inflammatory cells. Proc Am Thorac Soc. $2004 ; 1(3)$ : 239-246.

7. Kumar R, Thompson EB. The structure of the nuclear hormone receptors. Steroids. 1999; 64(5): 310-319.

8. Pratt WB, Toft DO. Steroid receptor interactions with heat shock protein and immunophilin chaperones. Endocr Rev. 1997; 18(3): 306360 .

9. Reichardt HM, Tuckermann JP, Göttlicher M, Vujic M, Weih F, Angel $\mathrm{P}$, et al. Repression of inflammatory responses in the absence of DNA binding by the glucocorticoid receptor. EMBO J. 2001; 20(24): 71687173. 
10. Pelaia G, Vatrella A, Cuda G, Maselli R, Marsico SA. Molecular mechanisms of corticosteroid actions in chronic inflammatory airway diseases. Life Sci. 2003; 72(14): 1549-1561.

11. Caratti G, Matthews L, Poolman T, Kershaw S, Baxter M, Ray D. Glucocorticoid receptor function in health and disease. Clin Endocrinol (Oxf). 2015. doi: 10.1111/cen.12728.

12. Adcock IM, Lane SJ. Corticosteroid-insensitive asthma: molecular mechanisms. J Endocrinol. 2003; 178(3): 347-355.

13. Leung DY, Bloom JW. Update on glucocorticoid action and resistance. J Allergy Clin Immunol. 2003; 111(1): 3-22.

14. Ratman D, Vanden Berghe W, Dejager L, Libert C, Tavernier J, Beck IM, et al. How glucocorticoid receptors modulate the activity of other transcription factors: a scope beyond tethering. Mol Cell Endocrinol. 2013; 380(1-2): 41-54. doi: 10.1016/j.mce.2012.12.014.

15. Oakley RH, Sar M, Cidlowski JA. The human glucocorticoid receptor beta isoform. Expression, biochemical properties, and putative function. J Biol Chem. 1996; 271(16): 9550-9559.

16. Cosío BG, Torrego A, Adcock IM. [Molecular mechanisms of glucocorticoids]. Arch Bronconeumol. 2005; 41(1): 34-41.

17. Smith DF, Toft DO. Steroid receptors and their associated proteins Mol Endocrinol. 1993; 7(1): 4-11.

18. Aijaz S, Balda MS, Matter K. Tight junctions: molecular architecture and function. Int Rev Cytol. 2006; 248: 261-298.

19. Erickson KK, Sundstrom JM, Antonetti DA. Vascular permeability in ocular disease and the role of tight junctions. Angiogenesis. 2007; 10(2): 103-117.

20. Matter K, Balda MS. Signalling to and from tight junctions. Nat Rev Mol Cell Biol. 2003; 4: 225-236.

21. Felinski EA, Cox AE, Phillips BE, Antonetti DA. Glucocorticoids induce transactivation of tight junction genes occludin and claudin-5 in retinal endothelial cells via a novel cis-element. Exp Eye Res. 2008; 86(6): 867-878. doi: 10.1016/j.exer.2008.01.002.

22. Johnson GL, Lapadat R. Mitogen-activated protein kinase pathways mediated by ERK, JNK, and p38 protein kinases. Science. 2002. 298(5600): 1911-1912.

23. Clark AR, Dean JL, Saklatvala J. Post-transcriptional regulation of gene expression by mitogen-activated protein kinase p38. FEBS Lett. 2003; 546(1): 37-44.

24. Rincón M, Flavell RA, Davis RA. The JNK and P38 MAP kinase signaling pathways in T cell-mediated immune responses. Free Radic Biol Med. 2000; 28(9): 1328-1337.

25. Ip YT, Davis RJ. Signal transduction by the c-Jun N-terminal kinase (JNK)--from inflammation to development. Curr Opin Cell Biol. 1998; 10(2): 205-219.

26. Kagoshima M, Ito K, Cosio B, Adcock IM. Glucocorticoid suppression of nuclear factor-kappa B: a role for histone modifications. Biochem Soc Trans. 2003; 31(1): 60-65.

27. Ito K, Barnes PJ, Adcock IM. Glucocorticoid receptor recruitment of histone deacetylase 2 inhibits interleukin-1beta-induced histone $\mathrm{H} 4$ acetylation on lysines 8 and 12. Mol Cell Biol. 2000; 20(18): 68916903.

28. Buttgereit F, Straub RH, Wehling M, Burmester GR. Glucocorticoids in the treatment of rheumatic diseases: an update on the mechanisms of action. Arthritis Rheum. 2004; 50(11): 3408-3417.
29. Buttgereit F, Scheffold A. Rapid glucocorticoid effects on immune cells. Steroids. 2002; 67(6): 529-534.

30. Hafezi-Moghadam A, Simoncini T, Yang Z, Limbourg FP, Plumier JC, Rebsamen MC, et al. Acute cardiovascular protective effects of corticosteroids are mediated by non-transcriptional activation of endothelial nitric oxide synthase. Nat Med. 2002; 8(5): 473-9.

31. Croxtall JD, Choudhury Q, Flower RJ. Glucocorticoids act within minutes to inhibit recruitment of signalling factors to activated EGF receptors through a receptor-dependent, transcription-independent mechanism. Br J Pharmacol. 2000; 130(2): 289-98.

32. Nieman LK, Chrousos GP, Kellner C, Spitz IM, Nisula BC, Cutler GB, et al. Successful treatment of Cushing's syndrome with the glucocorticoid antagonist RU 486. J Clin Endocrinol Metab. 1985; 61(3): 536-540.

33. Buttgereit F, Burmester GR, Brand MD. Bioenergetics of immune functions: fundamental and therapeutic aspects. Immunol Today. 2000; 21(4): 192-199.

34. Bartholome B, Spies CM, Gaber T, Schuchmann S, Berki T, Kunkel D, et al. Membrane glucocorticoid receptors (mGCR) are expressed in normal human peripheral blood mononuclear cells and up-regulated after in vitro stimulation and in patients with rheumatoid arthritis. FASEB J. 2004; 18(1): 70-80.

35. Orchinik M, Murray TF, Moore FL. A corticosteroid receptor in neuronal membranes. Science. 1991; 252(5014): 1848-1851.

36. Gametchu B, Watson C, Wu S. Use of receptor antibodies to demonstrate membrane glucocorticoid receptor in cells from human leukemic patients. FASEB J. 1993; 7(13): 1283-1292.

37. Chen F, Watson CS, Gametchu B. Association of the glucocorticoid receptor alternatively-spliced transcript $1 \mathrm{~A}$ with the presence of the high molecular weight membrane glucocorticoid receptor in mouse lymphoma cells. Journal of cellular biochemistry. 1999; 74(3): 430446.

38. Sackey FN, Watson CS, Gametchu B. Cell cycle regulation of membrane glucocorticoid receptor in CCRF-CEM human ALL cells: correlation to apoptosis. Am J Physiol. 1997; 273(1): E571-583.

39. Löwenberg M, Tuynman J, Bilderbeek J, Gaber T, Buttgereit F, van Deventer S, et al. Rapid immunosuppressive effects of glucocorticoids mediated through Lck and Fyn. Blood. 2005; 106: 1703-1710.

40.Löwenberg M, Verhaar AP, Bilderbeek J, Marle Jv, Buttgereit F, Peppelenbosch MP, et al. Glucocorticoids cause rapid dissociation of a T-cell-receptor-associated protein complex containing LCK and FYN. EMBO Rep. 2006; 7(10): 1023-1029.

41. Leahy KM, Koki AT, Masferrer JL. Role of cyclooxygenases in angiogenesis. Curr Med Chem. 2000; 7(11): 1163-1170.

42. Sone H, Okuda Y, Kawakami Y, Yamashita K. Effects of high glucose concentration and a thromboxane synthase inhibitor on the production of thromboxane A2 and prostaglandin I 2 and E2 by retinal endothelial cells. Life Sci. 1996; 58(3): 239-243.

43. Rymaszewski Z, Szymanski PT, Abplanalp WA, Myatt L, Di Salvo J, Cohen RM. Human retinal vascular cells differ from umbilical cells in synthetic functions and their response to glucose. Proc Soc Exp Biol Med. 1992; 199(2): 183-191.

44. Bazan NG, Allan G. Signal transduction and gene expression in the eye: a contemporary view of the pro-inflammatory, anti-inflammatory and modulatory roles of prostaglandins and other bioactive lipids. Surv Ophthalmol. 1997; 41 Suppl 2: S23-34.

45. Eakins KE. Prostaglandin and non-prostaglandin mediated 
breeakdown of the blood-aqueous barrier. Exp Eye Res. 1977; 25 Suppl: 483-498.

46. Kulkarni PS, Srinivasan BD. Cyclooxygenase and lipoxygenase pathways in anterior uvea and conjunctiva. Prog Clin Biol Res. 1989; 312: 39-52.

47. Angerman-Stewart JA, Eling TE, Glasgow WC. Prostaglandin $\mathrm{H}$ synthase-2 is induced in Syrian hamster embryo cells in response to basic fibroblast growth factor. Arch Biochem Biophys. 1995; 318(2): 378-386.

48. Arias-Negrete S, Keller K, Chadee K. Proinflammatory cytokines regulate cyclooxygenase-2 mRNA expression in human macrophages. Biochem Biophys Res Commun. 1995; 208(2): 582-589.

49. Corbett JA, Kwon G, Turk J, McDaniel ML. IL-1 beta induces the coexpression of both nitric oxide synthase and cyclooxygenase by islets of Langerhans: activation of cyclooxygenase by nitric oxide. Biochemistry. 1993; 32(50): 13767-13770.

50.Xie WL, Chipman JG, Robertson DL, Erikson RL, Simmons DL Expression of a mitogen-responsive gene encoding prostaglandin synthase is regulated by mRNA splicing. Proc Natl Acad Sci U S A. 1991; 88(7): 2692-2696.

51. Bazan N, Allan G, Marcheselli V. An inhibitor of injury-induced COX2 transcriptional activation elicits neuroprotection in a brain damage model. Improved Non-Steroid Anti-Inflammatory Drugs: COX-2 Enzyme Inhibitors. 1996; Springer. 145-166.

52. Dubois RN, Abramson SB, Crofford L, Gupta RA, Simon LS, Van De Putte LB, et al. Cyclooxygenase in biology and disease. FASEB J. 1998; 12(12): 1063-1073.

53. Dégi R, Thore C, Bari F, Thrikawala N, Nógrádi A, Robins G et al Ischemia increases prostaglandin $\mathrm{H}$ synthase-2 levels in retina and visual cortex in piglets. Graefes Arch Clin Exp Ophthalmol. 2001; 239(1): 59-65.

54.Tsujii M, Kawano S, Tsuji S, Sawaoka H, Hori M, DuBois RN Cyclooxygenase regulates angiogenesis induced by colon cancer cells. Cell. 1998; 93(5): 705-716.

55. Masferrer JL, Leahy KM, Koki AT, Zweifel BS, Settle SL, Woerner BM, et al. Antiangiogenic and antitumor activities of cyclooxygenase-2 inhibitors. Cancer Res. 2000; 60: 1306-1311.

56. Leahy KM, Ornberg RL, Wang Y, Zweifel BS, Koki AT, Masferrer JL. Cyclooxygenase-2 inhibition by celecoxib reduces proliferation and induces apoptosis in angiogenic endothelial cells in vivo. Cancer Res. 2002; 62: 625-631.

57. Kalgutkar AS, Crews BC, Rowlinson SW, Garner C, Seibert K, Marnett LJ. Aspirin-like molecules that covalently inactivate cyclooxygenase-2. Science. 1998; 280: 1268-1270.

58. Riendeau D, Percival MD, Boyce S, Brideau C, Charleson S, Cromlish $\mathrm{W}$, et al. Biochemical and pharmacological profile of a tetrasubstituted furanone as a highly selective COX-2 inhibitor. Br J Pharmacol. 1997; 121: 105-117.

59. Kujubu DA, Herschman HR. Dexamethasone inhibits mitogen induction of the TIS10 prostaglandin synthase/cyclooxygenase gene. J Biol Chem. 1992; 267: 7991-7994.

60. Liu XH, Kirschenbaum A, Lu M, Yao S, Dosoretz A, Holland JF, et al. Prostaglandin E2 induces hypoxia-inducible factor-1alpha stabilization and nuclear localization in a human prostate cancer cell line. J Biol Chem. 2002; 277: 50081-50086.

61. Miller JW, Adamis AP, Shima DT, D’Amore PA, Moulton RS, O'Reilly MS, et al. Vascular endothelial growth factor/vascular permeability factor is temporally and spatially correlated with ocular angiogenesis in a primate model. Am J Pathol. 1994; 145(3): 574-84.

62. Sennlaub F, Valamanesh F, Vazquez-Tello A, El-Asrar AM, Checchin D, Brault $\mathrm{S}$, et al. Cyclooxygenase- 2 in human and experimental ischemic proliferative retinopathy. Circulation. 2003; 108: 198-204.

63. Barnes PJ1. Anti-inflammatory mechanisms of glucocorticoids. Biochem Soc Trans. 1995; 23: 940-945.

64.Guyre PM, Yeager MP, Munck A. Glucocorticoid effects on immune responses. Neuroimmune Biology. 2007; 7: 147-167.

65. Wang K, Wang Y, Gao L, Li X, Li M, Guo J. Dexamethasone inhibits leukocyte accumulation and vascular permeability in retina of streptozotocin-induced diabetic rats via reducing vascular endothelial growth factor and intercellular adhesion molecule-1 expression. Biol Pharm Bull. 2008; 31(8):1541-1546.

66. Wiegers GJ, Reul JM. Induction of cytokine receptors by glucocorticoids: functional and pathological significance. Trends Pharmacol Sci. 1998; 19: 317-321.

67. McKay LI, Cidlowski JA. CBP (CREB binding protein) integrates NFkappaB (nuclear factor-kappaB) and glucocorticoid receptor physical interactions and antagonism. Mol Endocrinol. 2000; 14: 1222-1234.

68. Doucas V, Shi Y, Miyamoto S, West A, Verma I, Evans RM. Cytoplasmic catalytic subunit of protein kinase A mediates cross-repression by NF-kappa B and the glucocorticoid receptor. Proc Natl Acad Sci U S A. 2000; 97: 11893-11898.

69. Göttlicher M, Heck S, Herrlich P. Transcriptional cross-talk, the second mode of steroid hormone receptor action. J Mol Med (Berl). 1998; 76: 480-489.

70. Ashwell JD, Lu FW, Vacchio MS. Glucocorticoids in T cell development and function*. Annu Rev Immunol. 2000; 18: 309-345.

71. Crispe IN1. Fatal interactions: Fas-induced apoptosis of mature T cells. Immunity. 1994; 1: 347-349.

72. Yang Y, MerÄłep M, Ware CF, Ashwell JD. Fas and activation-induced Fas ligand mediate apoptosis of $\mathrm{T}$ cell hybridomas: inhibition of Fas ligand expression by retinoic acid and glucocorticoids. J Exp Med. 1995; 181: 1673-1682.

73. Mittelstadt PR, Ashwell JD. Inhibition of AP-1 by the glucocorticoidinducible protein GILZ. J Biol Chem. 2001; 276: 29603-29610.

74. Cippitelli M, Sica A, Viggiano V, Ye J, Ghosh P, Birrer MJ, et al. Negative transcriptional regulation of the interferon-gamma promoter by glucocorticoids and dominant negative mutants of c-Jun. J Biol Chem. 1995; 270: 12548-12556.

75. Risau W, Flamme I. Vasculogenesis. Annu Rev Cell Dev Biol. 1995; 11: 73-91.

76. Risau W1. Mechanisms of angiogenesis. Nature. 1997; 386: 671-674.

77. Folkman J1. Angiogenesis in cancer, vascular, rheumatoid and other disease. Nat Med. 1995; 1: 27-31.

78. Giuliari GP, Guel DA, Cortez MA, Cortez RT. Selective and pan-blockade agents in the anti-angiogenic treatment of proliferative diabetic retinopathy: a literature summary. Can J Ophthalmol. 2010; 45: 501508.

79. Folkman J. Tumor angiogenesis: therapeutic implications. N Engl J Med. 1971; 285: 1182-1186.

80. Maglione D, Guerriero V, Viglietto G, Delli-Bovi P, Persico MG. Isolation 
of a human placenta cDNA coding for a protein related to the vascular permeability factor. Proc Natl Acad Sci U S A. 1991; 88: 9267-9271.

81. Shima DT, Adamis AP, Ferrara N, Yeo KT, Yeo TK, Allende R, et al Hypoxic induction of endothelial cell growth factors in retinal cells: identification and characterization of vascular endothelial growth factor (VEGF) as the mitogen. Mol Med. 1995; 1: 182-193.

82. Trinh XB, Tjalma WA, Vermeulen PB, Van den Eynden G, Van der Auwera I, Van Laere SJ, et al. The VEGF pathway and the AKT/mTOR/ p70S6K1 signalling pathway in human epithelial ovarian cancer. Br J Cancer. 2009; 100: 971-978.

83. Karar J, Maity A. PI3K/AKT/mTOR Pathway in Angiogenesis. Front Mol Neurosci. 2011; 4: 51.

84. Millauer B, Wizigmann-Voos S, Schnürch H, Martinez R, Møller NP, Risau W, et al. High affinity VEGF binding and developmental expression suggest Flk-1 as a major regulator of vasculogenesis and angiogenesis. Cell. 1993; 72: 835-846.

85. Jakeman LB, Winer J, Bennett GL, Altar CA, Ferrara N. Binding sites for vascular endothelial growth factor are localized on endothelial cells in adult rat tissues. J Clin Invest. 1992; 89: 244-253.

86. Ishida S, Usui T, Yamashiro K, Kaji Y, Amano S, Ogura Y, et al VEGF164-mediated inflammation is required for pathological, but not physiological, ischemia-induced retinal neovascularization. J Exp Med. 2003; 198: 483-489.

87. Takahashi T, Ueno H, Shibuya M. VEGF activates protein kinase C-dependent, but Ras-independent Raf-MEK-MAP kinase pathway for DNA synthesis in primary endothelial cells. Oncogene. 1999; 18: 2221-2230.

88. Folkman J, Langer R, Linhardt RJ, Haudenschild C, Taylor S. Angiogenesis inhibition and tumor regression caused by heparin or a heparin fragment in the presence of cortisone. Science. 1983; 221: 719-725.

89. Hadoke PW, Iqbal J, Walker BR. Therapeutic manipulation of glucocorticoid metabolism in cardiovascular disease. Br J Pharmacol. 2009; 156: 689-712.

90.Logie JJ, Ali S, Marshall KM, Heck MM, Walker BR, Hadoke PW. Glucocorticoid-mediated inhibition of angiogenic changes in human endothelial cells is not caused by reductions in cell proliferation or migration. PLoS One. 2010; 5: e14476.

91.GREEN JP. STEROID THERAPY AND WOUND HEALING IN SURGICAL PATIENTS. Br J Surg. 1965; 52: 523-525.

92. Rae M, Mohamad A, Price D, Hadoke PW, Walker BR, Mason JI, et al. Cortisol inactivation by 11-hydroxysteroid dehydrogenase- 2 may enhance endometrial angiogenesis via reduced thrombospondin-1 in heavy menstruation. J Clin Endocrinol Metab. 2009; 94(4): 14431450. doi: 10.1210/jc.2008-1879.

93. Carmeliet P1. Mechanisms of angiogenesis and arteriogenesis. Nat Med. 2000; 6: 389-395.

94. Kräling BM, Wiederschain DG, Boehm T, Rehn M, Mulliken JB, Moses MA. The role of matrix metalloproteinase activity in the maturation of human capillary endothelial cells in vitro. J Cell Sci. 1999; 112 : 15991609.

95. Firestone GL, Kapadia BJ. Minireview: Steroid/nuclear receptorregulated dynamics of occluding and anchoring junctions. Mol Endocrinol. 2014; 28: 1769-1784.

96. Heiss JD, Papavassiliou E, Merrill MJ, Nieman L, Knightly JJ, Walbridge $\mathrm{S}$, et al. Mechanism of dexamethasone suppression of brain tumor- associated vascular permeability in rats. Involvement of the glucocorticoid receptor and vascular permeability factor. J Clin Invest. 1996; 98(6): 1400-1408.

97. Kim H, Lee JM, Park JS, Jo SA, Kim YO, Kim CW, et al. Dexamethasone coordinately regulates angiopoietin-1 and VEGF: a mechanism of glucocorticoid-induced stabilization of blood-brain barrier. Biochem Biophys Res Commun. 2008; 372(1): 243-248. doi: 10.1016/j. bbrc.2008.05.025.

98. Newton R1. Molecular mechanisms of glucocorticoid action: what is important? Thorax. 2000; 55: 603-613.

99. Duma D, Jewell CM, Cidlowski JA. Multiple glucocorticoid receptor isoforms and mechanisms of post-translational modification. J Steroid Biochem Mol Biol. 2006; 102: 11-21.

100. Tasker JG, Di S, Malcher-Lopes R. Minireview: rapid glucocorticoid signaling via membrane-associated receptors. Endocrinology. 2006; 147(12): 5549-5556.

101. Gille J, Reisinger K, Westphal-Varghese B, Kaufmann R. Decreased mRNA stability as a mechanism of glucocorticoid-mediated inhibition of vascular endothelial growth factor gene expression by cultured keratinocytes. J Invest Dermatol. 2001; 117(6): 1581-1587.

102. Fischer S, Renz D, Schaper W, Karliczek GF. In vitro effects of dexamethasone on hypoxia-induced hyperpermeability and expression of vascular endothelial growth factor. Eur J Pharmacol. 2001; 411: 231-243.

103. Koedam JA, Smink JJ, van Buul-Offers SC. Glucocorticoids inhibit vascular endothelial growth factor expression in growth plate chondrocytes. Mol Cell Endocrinol. 2002; 197: 35-44.

104. Sears JE, Hoppe G. Triamcinolone acetonide destabilizes VEGF mRNA in Müller cells under continuous cobalt stimulation. Invest Ophthalmol Vis Sci. 2005; 46: 4336-4341.

105. Antonetti DA, Lieth E, Barber AJ, Gardner TW. Molecular mechanisms of vascular permeability in diabetic retinopathy. Semin Ophthalmol. 1999; $14: 240-248$.

106. Fanning AS, Mitic LL, Anderson JM. Transmembrane proteins in the tight junction barrier. J Am Soc Nephrol. 1999; 10: 1337-1345.

107. Hirase T, Staddon JM, Saitou M, Ando-Akatsuka Y, Itoh M, Furuse M, et al. Occludin as a possible determinant of tight junction permeability in endothelial cells. J Cell Sci. 1997; 110 : 1603-1613.

108. Konari K, Sawada N, Zhong Y, Isomura H, Nakagawa T, Mori M. Development of the blood-retinal barrier in vitro: formation of tight junctions as revealed by occludin and ZO-1 correlates with the barrier function of chick retinal pigment epithelial cells. Exp Eye Res. 1995; 61: 99-108.

109. Kiuchi-Saishin Y, Gotoh S, Furuse M, Takasuga A, Tano Y, Tsukita S. Differential expression patterns of claudins, tight junction membrane proteins, in mouse nephron segments. J Am Soc Nephrol. 2002; 13: 875-886.

110. Kollmar R, Nakamura SK, Kappler JA, Hudspeth AJ. Expression and phylogeny of claudins in vertebrate primordia. Proc Natl Acad Sci U S A. 2001; 98: 10196-10201.

111. Fanning AS, Ma TY, Anderson JM. Isolation and functional characterization of the actin binding region in the tight junction protein ZO-1. FASEB J. 2002; 16: 1835-1837.

112. Wittchen ES, Haskins J, Stevenson BR. Protein interactions at the tight junction. Actin has multiple binding partners, and ZO-1 forms independent complexes with ZO-2 and ZO-3. J Biol Chem. 1999; 274: 


\section{9-35185.}

113. Zhang X, Wang N, Schachat AP, Bao S, Gillies MC. Glucocorticoids: structure, signaling and molecular mechanisms in the treatment of diabetic retinopathy and diabetic macular edema. Curr Mol Med. 2014 Mar; 14(3): 376-84.

114. Antonetti DA, Wolpert EB, DeMaio L, Harhaj NS, Scaduto RC Jr. Hydrocortisone decreases retinal endothelial cell water and solute flux coincident with increased content and decreased phosphorylation of occludin. J Neurochem. 2002; 80: 667-677.

115. Ayroldi E, Cannarile L, Migliorati G, Nocentini G, Delfino DV, Riccardi C. Mechanisms of the anti-inflammatory effects of glucocorticoids: genomic and nongenomic interference with MAPK signaling pathways. FASEB J. 2012; 26: 4805-4820.

116. Romero IA, Radewicz K, Jubin E, Michel CC, Greenwood J, Couraud $\mathrm{PO}$, et al. Changes in cytoskeletal and tight junctional proteins correlate with decreased permeability induced by dexamethasone in cultured rat brain endothelial cells. Neurosci Lett. 2003 Jun 26; 344(2): 112-116.

117. Tian JY, Dong XG, Chen N, Xu HF, Yuan GQ. [Dexamethasone intensify the tight junctions in rat retinal vascular endothelial cells in vitro]. Zhonghua Yan Ke Za Zhi. 2007; 43: 646-650.

118. Choi DW, Maulucci-Gedde M, Kriegstein AR. Glutamate neurotoxicity in cortical cell culture. J Neurosci. 1987; 7: 357-368.

119. Bracken MB1. Treatment of acute spinal cord injury with methylprednisolone: results of a multicenter, randomized clinical trial. J Neurotrauma. 1991; 8 Suppl 1: S47-50.

120. Bhisitkul RB, Winn BJ, Lee OT, Wong J, Pereira Dde S, Porco TC, et al. Neuroprotective effect of intravitreal triamcinolone acetonide against photoreceptor apoptosis in a rabbit model of subretinal hemorrhage. Invest Ophthalmol Vis Sci. 2008; 49(9): 4071-4077. doi: 10.1167 /iovs.08-1892.

121. Pang D, Kocherginsky M, Krausz T, Kim SY, Conzen SD Dexamethasone decreases xenograft response to Paclitaxel through inhibition of tumor cell apoptosis. Cancer Biol Ther. 2006; 5: 933940 .

122. Adachi T, Teramachi M, Yasuda H, Kamiya T, Hara H. Contribution of p38 MAPK, NF-kB and glucocorticoid signaling pathways to ER stress-induced increase in retinal endothelial permeability. Arch Biochem Biophys. 2012; 520(1): 30-35. doi: 10.1016/j. abb.2012.01.014.

123. Barnes PJ. Corticosteroid resistance in airway disease. Proc Am Thorac Soc. 2004; 1: 264-268.

124. Choi DW, Rothman SM. The role of glutamate neurotoxicity in hypoxic-ischemic neuronal death. Annu Rev Neurosci. 1990; 13: 171-182.

125. Segura Torres JE, Chaparro-Huerta V, Rivera Cervantres MC, MontesGonzález R, Flores Soto ME, Beas-Zárate C. Neuronal cell death due to glutamate excitotocity is mediated by p38 activation in the rat cerebral cortex. Neurosci Lett. 2006; 403: 233-238.

126. Mirjany M, Ho L, Pasinetti GM. Role of cyclooxygenase-2 in neuronal cell cycle activity and glutamate-mediated excitotoxicity. J Pharmacol Exp Ther. 2002; 301: 494-500.

127. Shirasawa N, Yamanouchi H. Glucocorticoids induce glutamine synthetase in folliculostellate cells of rat pituitary glands in vivo and in vitro. J Anat. 1999; 194 : 567-577.

128. Demir MN, Acar U, Sobaci G, Pınarlı FA, Erginturk Acar D, Beyazyıldız
E, et al. The effects of commonly used intravitreal steroids on proliferation index of ciliary body-derived mesenchymal stem cells: an in vitro study. Cutan Ocul Toxicol. 2015; 1-5.

129. Vazquez-Tello A, Halwani R, Hamid Q, Al-Muhsen S. Glucocorticoid receptor-beta up-regulation and steroid resistance induction by IL17 and IL-23 cytokine stimulation in peripheral mononuclear cells. J Clin Immunol. 2013; 33(2): 466-478. doi: 10.1007/s10875-0129828-3.

130. Vazquez-Tello A, Semlali A, Chakir J, Martin JG, Leung DY, Eidelman $\mathrm{DH}$, et al. Induction of glucocorticoid receptor-beta expression in epithelial cells of asthmatic airways by T-helper type 17 cytokines. Clin Exp Allergy. 2010; 40: 1312-1322.

131. McKinley L, Alcorn JF, Peterson A, Dupont RB, Kapadia S, Logar A et al. TH17 cells mediate steroid-resistant airway inflammation and airway hyperresponsiveness in mice. J Immunol. 2008; 181: 40894097.

132. Adcock IM, Barnes PJ. Molecular mechanisms of corticosteroid resistance. Chest. 2008; 134: 394-401.

133. Gagliardo R, Chanez P, Vignola AM, Bousquet J, Vachier I, Godard $\mathrm{P}$, et al. Glucocorticoid receptor alpha and beta in glucocorticoid dependent asthma. Am J Respir Crit Care Med. 2000; 162: 7-13.

134. Leung DY, Hamid Q, Vottero A, Szefler SJ, Surs W, Minshall E, et al. Association of glucocorticoid insensitivity with increased expression of glucocorticoid receptor beta. J Exp Med. 1997; 186: 1567-1574.

135. Sousa AR, Lane SJ, Cidlowski JA, Staynov DZ, Lee TH. Glucocorticoid resistance in asthma is associated with elevated in vivo expression of the glucocorticoid receptor beta-isoform. J Allergy Clin Immunol. 2000; 105: 943-950.

136. Li LB, Leung DY, Martin RJ, Goleva E. Inhibition of histone deacetylase 2 expression by elevated glucocorticoid receptor beta in steroidresistant asthma. Am J Respir Crit Care Med. 2010; 182: 877-883.

137. Pujols L, Mullol J, Roca-Ferrer J, Torrego A, Xaubet A, Cidlowski JA, et al. Expression of glucocorticoid receptor alpha- and beta-isoforms in human cells and tissues. Am J Physiol Cell Physiol. 2002; 283: C1324-1331.

138. Shahidi H, Vottero A, Stratakis CA, Taymans SE, Karl M, Longui CA, et al. Imbalanced expression of the glucocorticoid receptor isoforms in cultured lymphocytes from a patient with systemic glucocorticoid resistance and chronic lymphocytic leukemia. Biochem Biophys Res Commun. 1999; 254(3): 559-565.

139. de Castro M, Elliot S, Kino T, Bamberger C, Karl M, Webster E, et al. The non-ligand binding beta-isoform of the human glucocorticoid receptor (hGR beta): tissue levels, mechanism of action, and potential physiologic role. Mol Med. 1996; 2: 597-607.

140. Gagliardo R, Vignola AM, Mathieu M. Is there a role for glucocorticoid receptor beta in asthma? Respir Res. 2001; 2: 1-4.

141. Oakley RH, Webster JC, Sar M, Parker CR Jr, Cidlowski JA. Expression and subcellular distribution of the beta-isoform of the human glucocorticoid receptor. Endocrinology. 1997; 138: 5028-5038.

142. Lewis-Tuffin LJ, CidlowskiJA. The physiology of human glucocorticoid receptor beta (hGRbeta) and glucocorticoid resistance. Ann N Y Acad Sci. 2006; 1069: 1-9.

143. van den Akker EL, Russcher

144. H, van Rossum EF, Brinkmann AO, de Jong FH, Hokken A, et al. Glucocorticoid receptor polymorphism affects transrepression but not transactivation. J Clin Endocrinol Metab. 2006; 91: 2800-2803. 
145. Schaaf MJ, Cidlowski JA. AUUUA motifs in the 3'UTR of human glucocorticoid receptor alpha and beta mRNA destabilizes mRNA and decrease receptor protein expression. Steroids. 2002; 67: 627636.
146. Tliba 0, Cidlowski JA, Amrani Y. CD38 expression is insensitive to steroid action in cells treated with tumor necrosis factor-alpha and interferon- gamma by a mechanism involving the up-regulation of the glucocorticoid receptor beta isoform. Mol Pharmacol. 2006; 69(2): 588-96. 